\title{
Barriers to Cataract Surgery Utilization Among Cataract Patients Attending Surgical Outreach Sites in Ethiopia: A Dual Center Study
}

\section{Zewdu Yenegeta Bizuneh (iD Girum W Gessesse Dereje Hayilu Anbesse}

Department of Ophthalmology, St. Paul's Hospital Millennium Medical College, Addis Ababa, Ethiopia
Correspondence: Zewdu Yenegeta Bizuneh

POB: $127 \mid$

Tel +251913416492

Email zewduyenegeta@gmail.com
Background: Cataract is the leading cause of avoidable blindness globally and in Africa. Various barriers limit access of cataract blind individuals to cataract surgery. This study aimed to determine the barriers to cataract surgery utilization among cataract blind patients presenting to campaign sites in Ethiopia.

Methods: An institution-based cross-sectional design study was conducted to select 209 patients. The study was conducted from July to August 2020. A structured questionnaire was used to collect socio-demographic data and barriers for not having cataract surgery. Physical examination such as visual acuity, slit lamp bio microscopy and direct ophthalmoscopy was done for all participants. Epi Info 7 was used for data entry and Statistical Package for Social Science/SPSS version 23 was used for analysis after data were exported. Descriptive methods were employed for analysis

Results: A total of 209 subjects were recruited in the study with a mean age of $64.2( \pm 14.6)$ years, with a range of 32-99 years. From the total study subjects, $53 \%$ were males and $40.2 \%$ were over 66 years old. Upon presentation to the campaign site, $33 \%$ of study subjects had visual acuity of operable eye under blindness category and half of the study subjects $(50.2 \%)$ had mature cataract. The most reported barriers were waiting until cataract becomes mature $(18.7 \%)$, fear of surgery complications $(16.7 \%)$, far from eye health institution $(16.4 \%)$ and lack of income/cost for surgery $(11.5 \%)$.

Conclusion: Recognizing the severity and the blindness burden of cataract in Ethiopia, creating public awareness, establishing eye health institutions, increasing the number of eye health professionals, increasing the quantity and the quality of cataract campaigns to alleviate these barriers are of paramount importance at the country level.

Keywords: barriers, cataract surgery utilization, Ethiopia

\section{Background}

Cataract is the leading cause of avoidable blindness globally and in Africa. ${ }^{1}$ Eye health problems, including blindness and visual impairment, are one of the major public health problems in Ethiopia. According to a nationwide survey conducted in 2006 , the prevalence of blindness in Ethiopia was found to be $1.6 \%$, and $50 \%$ of this was due to cataract. ${ }^{2}$ Taking the current estimated population size of Ethiopia (100 million) and the national rate of blindness at $1.6 \%$, it is estimated that there are about 1.6 million blind people overall and 800,000 cataract blind people in Ethiopia. The crude prevalence of all vision loss in Ethiopia according to a GBD estimate (2020) was $7.8 \%$ and that of blindness was $0.7 \%$. 
Surgery remains the only option for restoration of vision loss due to cataract and cataract surgery is one of the most cost-effective interventions in medicine. However, various factors limit access of cataract blind individuals to cataract surgery. Among barriers that are of particular importance in limiting access to cataract surgery worldwide are said to be lack of the service in the vicinity, lack of knowledge about cataract and its treatment, uncertainty over the quality of locally available services, transportation problems, and concerns over the cost of surgery. ${ }^{3}$

Lack of knowledge about cataract and concerns about the quality of local services appear to be the principal barriers to cataract surgery in rural China. ${ }^{4}$

Various studies in developing countries including Africa have shown cost, ${ }^{5-11}$ lack of knowledge, ${ }^{4,12,13}$ logistic constraints, lack of time, ${ }^{7}$ fear, ${ }^{10,11}$ lack of escort ${ }^{8}$ and female gender, as factors limiting surgical utilization. Women were found less likely to express a need for sight for fear of being seen as a burden., ${ }^{9,14}$ Knowledge of someone with unsuccessful operation, no perceived need, and failure to recall diagnosis have also been found as barriers for poor cataract surgery uptake. ${ }^{15}$ Attitudinal barriers were reported more often, rather than issues of accessibility or cost, as barriers to undergoing cataract surgery in a study from India. ${ }^{12}$

A study in Brazil showed that the barriers to cataract surgery were older age, greater distance to the hospital, municipalities with fewer inhabitants and fewer ophthalmic services. ${ }^{16}$

A study in Sri Lanka showed that fear of surgery, no desire to improve vision and lack of awareness were the most frequently reported barriers. ${ }^{17}$

Understanding factors that contribute to poor utilization of cataract surgical services in different localities is important because the factors may differ among various areas and it helps to address the factors leading to reduced burden of cataract blindness. Little is known about the relative impact of various potential barriers to seeking cataract surgical services in Ethiopia. In a population-based study to determine the barriers to use of general eye care services, indirect cost was found to be the primary reason. ${ }^{18}$ Another study conducted in central Ethiopia found cost as the major reason for cataract blind patients not undergoing surgical intervention $(91.8 \%)$ followed by insufficient family income in $78.1 \%$ of the participants. ${ }^{2}$

This study was conducted with the main objective to determine the barriers for cataract surgery utilization among cataract blind patients presenting to outreach sites in Ethiopia.

\section{Methods}

\section{Study Setting and Data Collection Procedures}

An institution-based cross-sectional design study was conducted in Fiche Town General Hospital, Oromia region, Central Ethiopia and Dubti General Hospital in Afar region in northern east Ethiopia. The study was conducted from July to August 2019. Patients attending a cataract surgical campaign diagnosed to have cataract and willing to participate in the study were included. Patients in the campaign who were too seriously ill to answer the study questionnaires were excluded from the study.

All study subjects with cataract were included in the study on their consecutive presentation during study periods of both campaign sites. The first campaign was conducted for one week at Fiche Hospital from July 5 to July 10, 2019 and during that, a total of 109 subjects with cataract was included in the study and give their interview and examinations. The campaign at Dubti Hospital was conducted between August 25 and 30, 2019 and a total of 100 study subjects were recruited. Therefore, the total sample size from both hospitals was 209. All patients who presented with cataract and fulfilled inclusion criteria participated in the study. All patients were scheduled to undergo cataract surgery (small incision cataract surgery (SICS) type) by two ophthalmologists, one at Fitche hospital and the other at Dubti Hospital. Data were collected at the screening site before patients entered into the operation theatre for the surgery.

Data collection was done using a structured questionnaire which was initially prepared in English and then translated into Amharic, Afaregna and Afan oromo local languages and re-translated to English to check consistency in meaning of words and concepts. Data collection included socio-demographic characteristics, physical examination such as visual acuity, slit lamp bio microscopy and direct ophthalmoscopy for all participants. The data collection was conducted by five trained ophthalmic nurses by face to face interview and trained optometrists supervised the data collection. Training was given to data collectors and supervisors for one day by the principal investigator on how to use the tools and the data collection procedure. The collected data were checked for 
completeness, accuracy and clarity on a daily basis and amendments was done at the spot.

\section{Statistical Analysis}

Data were entered by Epi Info version 7 and analyzed using SPSS version 23. This study was a descriptive study and analyzed by descriptive statistics such as mean, median, standard deviation and ranges to summarize the information.

\section{Operational Definition}

Immature Cataract: Partially opaque lens and surgery may or may not be indicated.

Mature Cataract: Completely opaque lens and surgery is usually indicated.

Hyper mature Cataract: The leakage of water from the lens leads to wrinkled and shrunken anterior capsule and surgery is indicated.

Mild visual impairment - Presenting visual acuity worse than $6 / 12$ to $6 / 18$.

Moderate visual impairment - Presenting visual acuity worse than $6 / 18$ to $6 / 60$.

Severe visual impairment - Presenting visual acuity worse than $6 / 60$ to $3 / 60$.

Blindness - Presenting visual acuity worse than 3/60.

\section{Ethics Approval and Consent to Participate}

The study was performed based on the guidelines of the Declaration of Helsinki. Ethical approval was obtained from Institutional Review Board (IRB) of SPHMMC. Permission and oral informed consent was also gained from each study participant. Moreover, the privacy of the study participants and confidentiality of the information gathered was maintained and assured.

\section{Results}

A total of 209 subjects were recruited in the study with a mean age of 64.2 and SD of 14.6 years, with a range of 32-99 years. From the total study subjects, 84 (40.2\%) were in the age group 66 years old and above. Male subjects were 111 in number which is about 53.1\% and more than three quarters of all study subjects were married which is about 175 or $83.7 \%$. In terms of educational status, only 42 subjects or $22 \%$ have got primary education and above in their life (Table 1).
Table I Socio-Demography of Study Subjects, $2020(n=209)$

\begin{tabular}{|c|c|c|}
\hline Variables & Frequency & Percentage \\
\hline \multicolumn{3}{|l|}{ Age } \\
\hline Up to 50 & 43 & 20.6 \\
\hline $5 I-65$ & 82 & 39.2 \\
\hline 66 and above & 84 & 40.2 \\
\hline \multicolumn{3}{|l|}{ Sex } \\
\hline Male & 111 & 53.1 \\
\hline Female & 98 & 46.9 \\
\hline \multicolumn{3}{|l|}{ Marital status } \\
\hline Single & 4 & 1.9 \\
\hline Married & 175 & 83.7 \\
\hline Divorced & 12 & 5.7 \\
\hline Widowed & 18 & 8.6 \\
\hline \multicolumn{3}{|l|}{ Occupation } \\
\hline No & 34 & 16.3 \\
\hline Farmer & 156 & 74.6 \\
\hline Government employee & 15 & 7.2 \\
\hline Others & 4 & 1.9 \\
\hline \multicolumn{3}{|l|}{ Educational status } \\
\hline No & 163 & 78.0 \\
\hline Primary & 30 & 14.4 \\
\hline Secondary & 9 & 4.3 \\
\hline College and above & 7 & 3.3 \\
\hline
\end{tabular}

Upon presentation to the outreach site, visual acuity of operable eye was in blindness category for 69 subjects or $33 \%$. Half of the study subjects $(105 ; 50.2 \%)$ had mature cataract and 44 or $21.1 \%$ had hyper mature cataract. The duration for loss of vision among study subjects was more than two years for $45(21.5 \%)$ individuals. A total of 112 $(53.6 \%)$ subjects presented with unilateral operable cataract. One hundred and two subjects have pseudo exfoliation syndrome on their cataractous eye and 102 also had ocular co-morbidities in addition to the cataract (Table 2).

The participants of the current study reported different barriers to utilize cataract surgery on time. The most reported barriers were waiting until the cataract becomes mature $(39 ; 18.7 \%)$, fear of surgery complications (35; $16.7 \%$ ), far distance from eye health institution (34; $16.4 \%$ ) and unable to access cataract surgery service (26; $12.4 \%$ ). The least barriers listed by subjects were lack of cataract awareness which was reported by 5 (2.4\%). About $8(3.8 \%)$ patients believed that cataract is the will of God and no need of undergoing surgery (Figure 1). 
Table 2 Clinical Presentations of Study Subjects, $2020(n=209)$

\begin{tabular}{|c|c|c|}
\hline Variables & Frequency & Percentage \\
\hline \multicolumn{3}{|c|}{ Operable eye Unaided VA } \\
\hline Up to $6 / 60$ & 76 & 36.4 \\
\hline $6 / 60-3 / 60$ & 64 & 30.6 \\
\hline 3/60-LP & 69 & 33.0 \\
\hline \multicolumn{3}{|c|}{ Maturity of cataract } \\
\hline Immature & 60 & 28.7 \\
\hline Mature & 105 & 50.2 \\
\hline Hyper mature & 44 & 21.1 \\
\hline \multicolumn{3}{|c|}{ Duration of cataract in months } \\
\hline Up to 6 & 55 & 26.3 \\
\hline $7-12$ & 63 & 30.1 \\
\hline $13-24$ & 46 & 22.0 \\
\hline 25 and above & 45 & 21.5 \\
\hline \multicolumn{3}{|l|}{ Laterality } \\
\hline Unilateral & 112 & 53.6 \\
\hline Bilateral & 97 & 46.4 \\
\hline \multicolumn{3}{|c|}{ Presence of Pseudo exfoliation } \\
\hline Yes & 102 & 49.0 \\
\hline No & 106 & 51.0 \\
\hline \multicolumn{3}{|c|}{ Ocular co-morbidity } \\
\hline Yes & 102 & 48.8 \\
\hline No & 107 & 51.2 \\
\hline
\end{tabular}

The most prevalent reasons or barriers mentioned for not having cataract surgery among males were further location from eye health institutions $(22 ; 64.7 \%)$, fear of cataract surgical complications $(21 ; 60.0 \%)$ and waiting for cataract to get mature $(20 ; 51.3 \%)$. For females waiting cataract to get mature $(19 ; 48.7 \%)$ was the most commonly mentioned reason followed by fear of surgery complications $(14 ; 40.0 \%)$ and further location from eye health institutions (12; 53.3\%) (Table 3).

Most of the reasons or barriers to cataract surgery were reported in age group of 66 years and above. Twenty-two subjects with age 66 and above or $56.4 \%$ of the three age categories pointed out that the main reason for not having cataract surgery was waiting until it becomes mature. Nineteen or $55.9 \%$ indicated further location of their home from eye health center was their main reason for not having surgery. Only 8 individuals or $22.9 \%$ from the three age group fear for surgical complications among age group of 50 and below, whereas $10(28.6 \%)$ fear that among the age group between 51 and 65 years (Table 4).

\section{Discussions}

This outreach based cross-sectional study tried to explore barriers for cataract surgery utilization among cataract patients attending two surgical outreach sites in Ethiopia. The most reported barriers were waiting until the cataract becomes mature $(39 ; 18.7 \%)$, fear of surgery complications (35; 16.7\%), far from eye health institution ( $34 ; 16.4 \%)$, do not know where to get service (26; 12.4\%), lack of income/ cost for surgery $(24 ; 11.5 \%)$, preferred doctors' appointment $(24 ; 11.5 \%)$, lack of faith $(21 ; 10.1 \%)$, lack of transportation $(21 ; 10.1 \%)$, know someone with unsuccessful surgery (20; 9.6\%), can see well with better eye (19;9.1\%) and being told that cataract was not mature $(18 ; 8.6 \%)$.

Waiting for the cataract until it becomes mature was the most common reported barrier for cataract surgery utilization in this study. This might be due to the fact that the outreach sites are known to be with high burden of cataract blindness in the country and as a result, the professionals gave priority to operate on the patients with mature cataract and those diagnosed to have immature cataract were followed. ${ }^{19}$

Fear of surgery complications was another reason mentioned as a barrier for not having cataract surgery and this is supported by studies in other areas. This finding can be explained that poor knowledge of cataract, surgery and its complications can lead to fear which may prevent them not having cataract surgery and most of such patients present after their vision is considerably declined. ${ }^{7,8,10-13,17,19}$ This might be due to incorrect assumptions regarding the cataract surgery or due to poor quality of the previous surgical campaigns in the area.

Far distance from eye health institution was another barrier distinguished for non-cataract surgery utilization. This was particularly mentioned among the elderly (66 years old and above) and might be the elderly may find it difficult to walk to far areas and may be dependent on escorts. This is a common challenge in developing countries and was supported by different literatures. ${ }^{1,7,11,16}$ This might be due to lack of income for transportation and long duration of waiting time in the hospital makes the patient ignorant of the cataract surgery. The availability of eye health institutions on both sites in this study might be one more reason for delaying utilization of cataract. For instance, there is no health institution with cataract surgery 


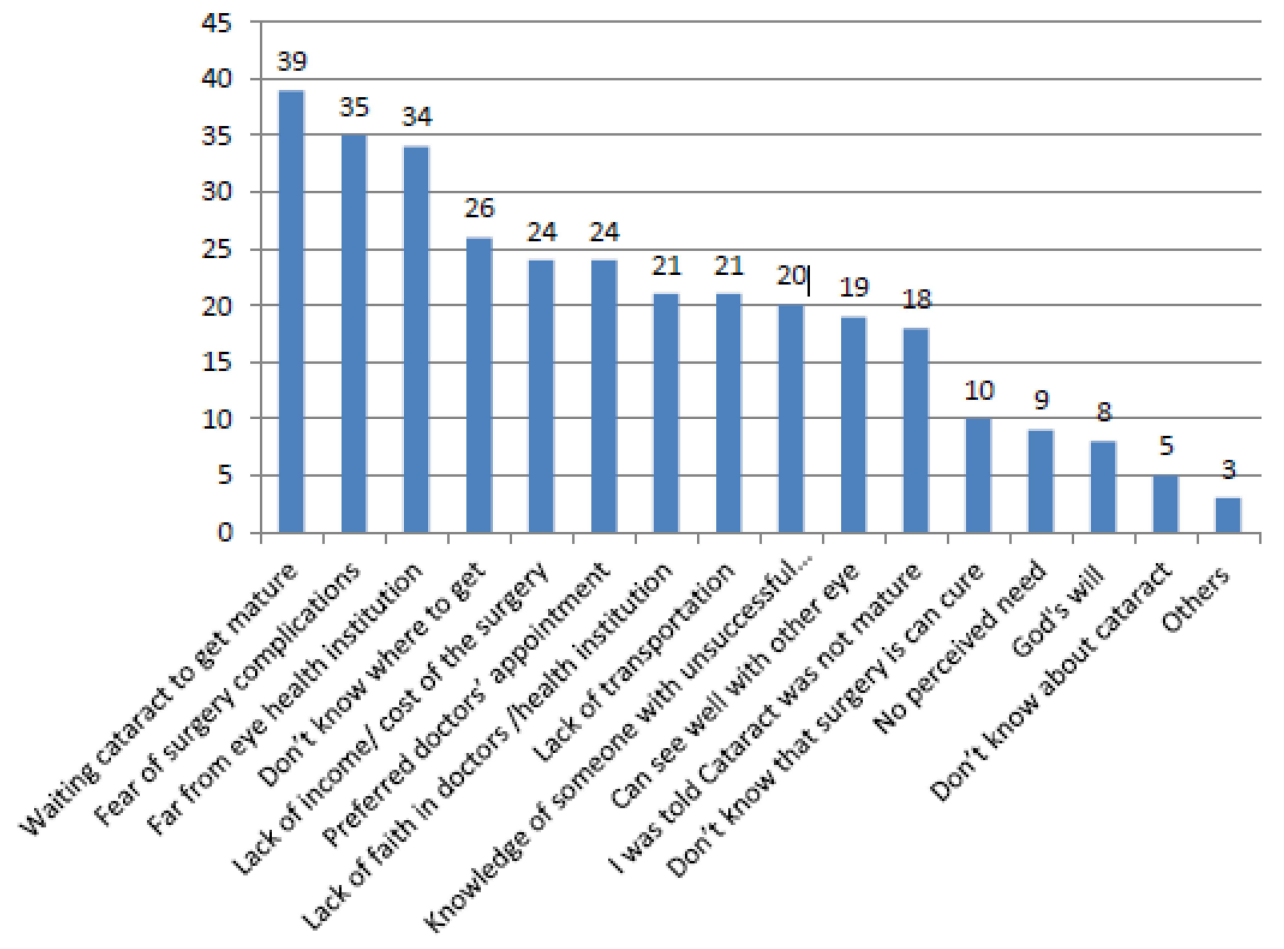

Figure I Barriers to cataract surgery among study subjects, $2020(n=209)$.

service in Afar region of Ethiopia where Dubti Hospital is located.

Lack of awareness regarding the place for cataract surgery was another barrier identified in this study. Both sites are further away from eye health institutions with cataract surgery services and also lack of eye health professionals can contribute for low awareness for cataract surgery. ${ }^{16,19}$
Lack of income/ cost of surgery were another barrier distinguished in this study. This was supported by different studies. $^{5-11,14,19,20}$ Lack of cataract awareness was another barrier distinguished in this study. This was supported by other studies. $4,8,12,15,17$ This might be due to lack of perceived knowledge of both the cataract and its treatment.

Generally, the barriers to uptake of cataract surgery was observed more in male study subjects than female.

Table 3 Barriers to Cataract Surgery Uptake in Terms of Sex Category Among Study Subjects, $2020(n=209)$

\begin{tabular}{|l|l|l|l|}
\hline Type of Reasons & Male & Female & Total \\
\hline Waiting cataract to get mature & $20(51.3 \%)$ & $19(48.7 \%)$ & $39(18.7 \%)$ \\
Fear of surgery complications & $21(60.0 \%)$ & $14(40.0 \%)$ & $35(16.7 \%)$ \\
Far from eye health institution & $22(64.7 \%)$ & $12(53.3 \%)$ & $34(16.3 \%)$ \\
Do not know where to get & $14(53.8 \%)$ & $12(46.2 \%)$ & $26(I 2.4 \%)$ \\
Lack of income/cost for surgery & $15(62.5 \%)$ & $9(37.5 \%)$ & $24(I I .5 \%)$ \\
Preferred doctors' appointment & $16(66.7 \%)$ & $8(33.3 \%)$ & $24(I 1.5 \%)$ \\
Lack of Faith & $13(61.9 \%)$ & $8(38.1 \%)$ & $21(10.1 \%)$ \\
Lack of transportation & $12(57.1 \%)$ & $9(42.9 \%)$ & $21(10.1 \%)$ \\
Know someone with unsuccessful surgery & $13(65.0 \%)$ & $7(35.0 \%)$ & $20(9.6 \%)$ \\
Can see well with better eye & $14(73.7 \%)$ & $5(26.3 \%)$ & $19(9.1 \%)$ \\
I was told cataract was not mature & $10(55.6 \%)$ & $8(44.4 \%)$ & $18(8.6 \%)$ \\
\hline
\end{tabular}


Table 4 Barriers to Cataract Surgery Uptake in Terms of Age Category Among Study Subjects, $2020(n=209)$

\begin{tabular}{|l|l|l|l|}
\hline Type of Reasons & Up to $\mathbf{5 0}$ Years & $\mathbf{5 I - 6 5}$ Years & $\mathbf{6 6}$ and Above Years \\
\hline Waiting cataract to get mature & $3(7.7 \%)$ & $14(35.9 \%)$ & $22(56.4 \%)$ \\
Fear of surgery complications & $8(22.9 \%)$ & $10(28.6 \%)$ & $17(48.6 \%)$ \\
Far from eye health institution & $5(14.7 \%)$ & $10(29.4 \%)$ & $19(55.9 \%)$ \\
Do not know where to get & $5(19.2 \%)$ & $7(26.9 \%)$ & $14(53.8 \%)$ \\
Lack of income/cost for surgery & $4(16.7 \%)$ & $11(45.8 \%)$ & $9(37.5 \%)$ \\
Preferred doctors' appointment & $6(25.0 \%)$ & $5(20.8 \%)$ & $13(54.2 \%)$ \\
Lack of Faith & $3(14.3 \%)$ & $8(38.1 \%)$ & $10(47.6 \%)$ \\
Lack of transportation & $4(19.0 \%)$ & $5(23.8 \%)$ & $12(57.1 \%)$ \\
Know someone with unsuccessful surgery & $3(15.0 \%)$ & $8(40.0 \%)$ & $9(45.0 \%)$ \\
Can see well with better eye & $5(26.3 \%)$ & $1 \mathrm{I}(57.9 \%)$ & $3(15.8 \%)$ \\
I was told cataract was not mature & $3(16.7 \%)$ & $7(38.9 \%)$ & $8(44.4 \%)$ \\
\hline
\end{tabular}

However, a comparative study reported that delaying for cataract surgery is more frequent among female population. The discrepancy might be explained that the cataract surgery uptake at campaign site is more utilized by males than females which may increase the proportion of the sample for delayance. ${ }^{12}$

Subjects with older age were also subjected for longer delay for cataract surgery than younger individuals. This is also true in the studies conducted in different places. The burden of cataract effect on visual function and its maturity increases with increasing of age. In this regard, being old can increase the dependency which may contribute for not having surgery on time. ${ }^{12,15}$

This study has certain limitations. The sample can be said to be low and there is no analytical analysis to explore the significant association variables so that it is impossible to extrapolate to a wider population.

\section{Conclusions and Recommendations}

Waiting until cataract becomes mature, fear of surgery complications, far distance from eye health institution, not knowing where to get the service, lack of income/cost for surgery, preferred doctors' appointment, lack of faith, lack of transportation, knowing someone with unsuccessful surgery, can see well with better eye and lack of cataract awareness were the major barriers identified. Recognizing the severity and the blindness burden of cataract in Ethiopia, creating public awareness, establishing eye health institutions, increasing the number of eye health professionals, increasing the quantity and the quality of cataract campaigns can have paramount importance to alleviate those barriers. In order to address the fear of surgery, it is important to ensure provision of consistently high-quality cataract surgery with good outcomes and also use of satisfied cataract operated patients with good outcomes as motivators for others to have surgery.

\section{Data Sharing Statement}

The dataset used and or analyzed during this study is available from the corresponding author on a reasonable request from Zewdu Yenegeta (contact address: Zewduyenegeta@gmail.com).

\section{Acknowledgments}

We would like to acknowledge all participants of the study who kindly volunteered to answer to the interview. Our gratitude also goes to data collectors for their tireless work during data collection.

\section{Author Contributions}

All authors made substantial contributions to conception and design, acquisition of data, or analysis and interpretation of data; took part in drafting the article or revising it critically for important intellectual content; agreed to submit to the current journal; gave final approval of the version to be published; and agree to be accountable for all aspects of the work.

\section{Disclosure}

The authors declare that they have no competing interests in this work.

\section{References}

1. Resnikoff S, Pascolini D, Etya'Ale D, et al. Global data on visual impairment in the year 2002. Bull World Health Organ. 2004;82:844-851.

2. Mehari ZA, Zewedu RTH, Gulilat FB. Barriers to cataract surgical uptake in central Ethiopia. Middle East Afr J Ophthalmol. 2013;20 (3):229. doi:10.4103/0974-9233.114798 
3. Yorston D. High-volume surgery in developing countries. Eye. 2005;19(10):1083-1089. doi:10.1038/sj.eye.6701966

4. Yin Q, Hu A, Liang Y, et al. A two-site, population-based study of barriers to cataract surgery in rural China. Invest Ophthalmol Vis Sci. 2009;50(3):1069-1075. doi:10.1167/iovs.08-2783

5. Malhotra R, Uppal Y, Misra A, Taneja D, Gupta V, Ingle G. Increasing access to cataract surgery in a rural area-a support strategy. Indian J Public Health. 2005;49(2):63-67.

6. Rotchford A, Rotchford K, Mthethwa L, Johnson G. Reasons for poor cataract surgery uptake-a qualitative study in rural South Africa. Trop Med Int Health. 2002;7(3):288-292. doi:10.1046/j.13653156.2002.00850.x

7. Snellingen T, Shrestha B, Gharti M, Shrestha J, Upadhyay M, Pokhrel R. Socioeconomic barriers to cataract surgery in Nepal: the South Asian cataract management study. Br J Ophthalmol. 1998;82 (12):1424-1428. doi:10.1136/bjo.82.12.1424

8. Gyasi M, Amoaku W, Asamany D. Barriers to cataract surgical uptake in the upper east region of Ghana. Ghana Med J. 2007;41:4.

9. Courtright P, Kanjaloti S, Lewallen S. Barriers to acceptance of cataract surgery among patients presenting to district hospitals in rural Malawi. Trop Geogr Med. 1995;47(1):15-18.

10. Chandrashekhar TS, Bhat HV, Pai RP, Nair SK. Coverage, utilization and barriers to cataract surgical services in rural South India: results from a population-based study. Public Health. 2007;121(2):130-136. doi:10.1016/j.puhe.2006.07.027

11. Sapkota YD, Pokharel GP, Dulal S, Byanju RN, Maharjan IM. Barriers to up take cataract surgery in Gandaki Zone, Nepal. Kathmandu Univ Med J. 2004;2(2):103-112.

12. Dhaliwal U, Gupta SK. Barriers to the uptake of cataract surgery in patients presenting to a hospital. Indian J Ophthalmol. 2007;55 (2):133. doi:10.4103/0301-4738.30708
13. Dandona R, Dandona L, John RK, McCarty CA, Rao GN. Awareness of eye diseases in an urban population in southern India. Bull World Health Organ. 2001;79(2):96.

14. Geneau R, Lewallen S, Bronsard A, Paul I, Courtright P. The social and family dynamics behind the uptake of cataract surgery: findings from Kilimanjaro region, Tanzania. $B r J$ Ophthalmol. 2005;89 (11):1399-1402. doi:10.1136/bjo.2005.075572

15. Krakauer M, Pendurthi B, Hay-Smith G, Barton K, Budenz D. Barriers to the uptake of cataract surgery in an Urban West African community. Invest Ophthalmol Vis Sci. 2008;49(13):1931.

16. de Almeida Ferreira G, Schaal LF, Ferro MD, Rodrigues ACL, Khandekar R, Schellini SA. Outcomes of and barriers to cataract surgery in Sao Paulo State, Brazil. BMC Ophthalmol. 2017;17 (1):1-7. doi:10.1186/s12886-017-0637-6

17. Athanasiov PA, Edussuriya K, Senaratne T, Sennanayake S, Selva D, Casson RJ. Cataract in central Sri Lanka: cataract surgical coverage and self-reported barriers to cataract surgery. Clin Experiment Ophthalmol. 2009;37(8):780-784. doi:10.1111/j.14429071.2009.02152.x

18. Melese M, Alemayehu W, Friedlander E, Courtright P. Indirect costs associated with accessing eye care services as a barrier to service use in Ethiopia. Trop Med Int Health. 2004;9(3):426-431. doi:10.1111/ j.1365-3156.2004.01205.x

19. Vaidyanathan K, Limburg H, Foster A, Pandey R. Changing trends in barriers to cataract surgery in India. Bull World Health Organ. 1999;77(2):104.

20. Venkataswamy PG, Billiant G. Social and economic barriers to cataract surgery in rural south India: a preliminary report. J Vis Impair Blind. 1981;75(10):405-408. doi:10.1177/0145482X8107501005
Clinical Optometry

\section{Publish your work in this journal}

Clinical Optometry is an international, peer-reviewed, open access journal publishing original research, basic science, clinical and epidemiological studies, reviews and evaluations on clinical optometry. All aspects of patient care are addressed within the journal as well as the practice of optometry including economic and business analyses. Basic and clinical research papers are published that cover

Submit your manuscript here: https://www.dovepress.com/clinical-optometry-journal all aspects of optics, refraction and its application to the theory and practice of optometry. The manuscript management system is completely online and includes a very quick and fair peer-review system, which is all easy to use. Visit http://www.dovepress.com/ testimonials.php to read real quotes from published authors. 